\title{
Does ethnicity matter in male hormonal contraceptive efficacy?
}

\author{
Niloufar Ilani ${ }^{1}$, Peter Y Liu' ${ }^{2}$, Ronald S Swerdloff ${ }^{1}$ and Christina Wang ${ }^{1}$
}

The development of male hormonal contraception has progressed significantly during the last three decades. The ultimate goal is to produce an effective, safe and reversible male method of contraception that are within reach of and can be used by all men globally. This review aims to outline the recent developments in male hormonal contraception with special emphasis on how ethnicity influences acceptability, extent of sperm suppression, and rate of recovery of spermatogenesis. Baseline differences in testicular histomorphology and testosterone metabolism between East Asian and Caucasian men have been reported, but whether this contributes significantly to varying degrees of sperm suppression in response to exogenous testosterone therapy is less known. Testosterone alone male hormonal contraceptive regimens are effective and applicable for East Asian men, and less so for Caucasians. Combinations of progestins with androgens are sufficient to optimize effectiveness of suppression and applicability to all ethnicities. New compounds such as steroidal or non-steroidal selective androgen receptor modulators with dual androgenic and progestational activities are potential compounds for further development as male hormonal contraceptive methods. At the present time, combined androgen and progestin contraceptive regimens appear to be effective, safe, reversible and convenient to use for all men with ethnic, cultural and environmental differences. Further refinements on the hormonal agent, methods of delivery, and dose optimization of the androgen relative to the progestin are necessary. This goal mandates further investment and large clinical trials in multiethnic populations to better define safety and efficacy. Asian Journal of Andrology (2011) 13, 579-584; doi:10.1038/aja.2010.133; published online 14 February 2011

Keywords: azoospermia; male contraception; progestin; suppression of spermatogenesis; testosterone

\section{INTRODUCTION}

Unintended pregnancy is an important global problem. Hormonal contraceptives are some of the most effective reversible methods for women. In contrast, from a market-ready standpoint, male contraceptive methods are limited to condom or vasectomy, the former suffers from high failure rate or while the latter has a high irreversibility rate. Our failure to bring a male directed hormonal contraceptive to the public is disappointing on this the fiftieth anniversary of the female directed oral contraceptive pill. Male hormonal contraceptives through administration of exogenous testosterone either alone or in combination with a progestin or gonadotropin releasing hormone analog will suppress gonadotropins (luteinizing hormone (LH) and follicle-stimulating hormone) and intratesticular testosterone to levels below that required to support spermatogenesis. Exogenously administered testosterone maintains sexual function and other androgenic effects on other reproductive and non-reproductive target organs without supporting spermatogenesis. ${ }^{1-7}$ Studies from our group and others showed that low intratesticular testosterone levels decrease spermatogonia proliferation, accelerate apoptosis, and result in defects in spermiation and sequestration of mature spermatozoa by Sertoli cells. $^{8-14}$

Two landmark contraceptive efficacy studies of testosterone induced azoospermia and severe oligozoospermia conducted by WHO (World Health Organization) in 1990s showed conclusively that when spermatogenesis is severely suppressed by exogenous intramuscular administration of testosterone in healthy men, contraceptive efficacy comparable to hormonal contraceptive methods for women can be achieved. ${ }^{15,16}$ Since then three contraceptive efficacy studies have been conducted that confirmed the effectiveness of hormonal male contraception. ${ }^{17-19}$ These have been supported by the Chinese Government, WHO and other non-government organizations. However, it should be noted that the majority of men participating in these more recent contraceptive efficacy studies originated from China. ${ }^{18-21}$ Ethnicity is an important consideration for the development of a universally applicable male hormonal contraceptive that can be utilized throughout both the developed and developing world. Potential ethnic influences include acceptability of the method by men and their partners; ease of use of certain regimens and delivery methods (e.g. injections versus other pills); rapidity or extent of suppression of sperm output; effectiveness of suppression of spermatogenesis by different hormonal regimens; and reversibility of spermatogenesis after cessation of male hormonal contraception. Whether optimization of treatment regimens or dosages of the steroid hormones can overcome these ethnic differences is unclear. In this review, we have elected to focus on the influence of ethnicity on male contraceptive development and highlight the leadership role of East Asian investigators and the supportive government and non-government organizations in accelerating progress of this field. For the purpose

${ }^{1}$ Division of Endocrinology, Department of Medicine, Harbor-UCLA Medical Center and Los Angeles Biomedical Research Institute, Torrance, CA 90509, USA and ${ }^{2}$ Endocrine and Metabolic Research Program, Woolcock Institute of Medical Research, University of Sydney, Sydney 2050, Australia Correspondence: Dr C Wang (wang@labiomed.org)

Received: 13 October 2010; Revised: 1 December 2010; Accepted: 20 December 2010; Published online: 14 February 2011 
of this review East Asian men refer to men mainly from China and Indonesia and Caucasian men refer to white men with European ancestry. In addition, we use efficacy for contraceptive efficacy and effectiveness to denote adequate suppression of sperm concentration to levels that are compatible with contraceptive efficacy.

\section{ETHNIC DIFFERENCES IN ACCEPTABILITY OF MALE CONTRACEPTIVE METHODS}

The efficacy of any contraceptive method depends on the acceptability of the method and adherence to and continued use of the regimen by the target population which includes both men and their partners. ${ }^{22}$ In a cross-cultural survey of 1829 white, colored, black, East Asian and other men in Edinburgh, United Kingdom; Cape Town, South Africa; Shanghai and Hong Kong, China, supported by the UK government, the majority welcomed a new male hormonal method and $44-83 \%$ stated that they would use an oral form of male hormonal contraception. ${ }^{23}$ There were significant differences in perceived contraceptive efficacy, convenience, and change in sexual satisfaction and masculinity among the different ethnic groups. Only $36-38 \%$ of men in Hong Kong felt that male hormonal contraceptive would be effective for pregnancy prevention. Condom use was considered the most convenient contraceptive method in Chinese centers, while the majority of men in Edinburgh and Cape Town considered the male pill or an injectable to be more convenient. Contraceptive preference followed the same pattern as anticipated convenience. Condom use was the popular choice in Chinese men and black men in Cape Town, while novel hormonal methods were the first choice in Edinburgh and colored or white men in Cape Town. With regards to the preferred duration of long acting methods, the most popular interval was 3-6 months except in Shanghai where $42 \%$ preferred 3 -year implants. Novel male hormonal contraceptives were not favored by Chinese men; this may reflect their current method of contraception and knowledge of other female hormonal methods. For example, in Hong Kong over $60 \%$ of men were using condoms whereas in Shanghai, intrauterine devices were the most common method and only one couple was relying on female hormonal method. ${ }^{23}$

In an accompanying survey of the female partners (1894 women in same centers: Edinburgh, Cape Town, Hong Kong and Shanghai), responses remarkably similar to men were obtained. Twenty-nine percent of women in Hong Kong and 13\% of women in Shanghai were negative or unsure about the effectiveness of male hormonal contraceptives compared with 7 and $6 \%$ of female partners in Cape Town and Edinburgh, respectively. Overall more than one-third of women believed that male hormonal contraceptives would be used by the couple in the future, with the main exception being Hong Kong where only $14 \%$ of women responded positively. The response of Chinese women in Hong Kong also contrasted with Chinese women in Shanghai where $71 \%$ were agreeable to the future use of male methods. Chinese women were most concerned about side effects and associated health risks compared to women from Edinburgh or Cape Town where the concern was mostly lack of trust. ${ }^{22}$

In a survey of more than 9000 men from nine countries on four continents including Europe, North America, Central/South America and East Asia, 55\% of men interviewed reported willingness to use male hormonal method ranging from $28.5 \%$ in Indonesia as a representative of East Asian population to $71.4 \%$ in Spain. The oral route was the most preferred method compared to monthly injections or annual implants in all participating countries except in Indonesia where monthly injection and oral pills was equally desirable. Educational and income level, acceptance of vasectomy, and current use of contraception were important predictors of willingness to use a male hormonal contraceptive. ${ }^{24}$

\section{SUPPRESSION OF SPERMATOGENESIS: ADDING A PROGESTIN OVERCOMES ETHNIC DIFFERENCES}

Studies of androgen or androgen-progestin male hormonal contraceptive show that $80-95 \%$ of men will suppress sperm output to concentrations compatible with reliable contraception in clinical trials lasting up to 24 months. ${ }^{17-19}$ The effect of ethnicity is more evident on the degree of suppression when an androgen alone regime is used. Weekly injection of testosterone enanthate resulted in azoospermia in $91 \%$ of Chinese men compared to $60 \%$ of Non-Asian men mostly of European origin. More East Asian men than non-East Asian men remained consistently azoospermic (95\% compared to $68 \%$ ) once they reached azoospermia. ${ }^{15,16}$ Men who were azoospermic had faster rate of suppression of sperm output and also a faster rate of recovery but the variability in suppression to azoospermia was not explained by ethnic or anthropometric differences. Moreover the effect of testosterone on lipids and liver transaminases were different between the East Asians and Non-Asians. ${ }^{25,26}$

We expanded the findings from the WHO supported studies described above and did an integrated analysis of 1756 healthy eugonadal men (1108 Caucasians, 581 East Asians and 67 other ethnicities) treated with androgen alone (mainly with testosterone esters as injectables or testosterone as implants) or androgen-progestin (the progestins include depo-medroxyprogesterone acetate, levonorgestrel, desogestrel, and etonogestrel as oral pills, injectables or implants) male hormonal contraceptive regimens. In this analysis, we showed that the independent factors which most strongly influence the odds of eventual suppression are ethnicity and the use of a progestin as part of the treatment regimen (Table 1). ${ }^{27}$ This is illustrated by actual suppression

Table 1 Predictors of faster suppression and recovery of sperm output after cessation of male hormonal contraception

Independent predictors of eventual suppression of sperm output during male hormonal contraceptive

- Asian race

- Concurrent progestin use

- Lower body mass index

- Lower dose of testosterone

Independent predictors of faster suppression of sperm output

- Caucasian race

- Younger age

- Concurrent progestin use

- Shorter treatment duration

- Lower baseline sperm concentrations

- Lower baseline serum testosterone concentrations

- Depot testosterone preparations

Independent predictors of faster recovery of sperm output after cessation of MHC

- Asian race

- Older age

- Shorter treatment duration

- Higher baseline sperm concentrations

- Faster initial suppression of sperm output

- Lower baseline serum LH concentrations

- Shorter acting testosterone preparations

Abbreviations: LH, luteinizing hormone; MHC, male hormonal contraceptives 
rates observed in 1756 men treated with various male hormonal contraceptive regimens (Figure 1, using data from Ref. 27), which clearly shows that: (i) only up to $80 \%$ of Caucasian men suppress sperm output to $<10^{6} \mathrm{ml}^{-1}$ when received treatments that contain only androgens; (ii) up to $90 \%$ of East Asian men will adequately suppress sperm output when treated only with androgens; (iii) the addition of a progestin increases to over $90 \%$ the proportion of Caucasian men who eventually suppress sperm output to $<10^{6} \mathrm{ml}^{-1}$. This proportion exceeds that observed by East Asian men treated with androgens alone; and (iv) nearly all East Asian men treated with androgen-progestin male hormonal contraceptive will eventually suppress sperm output to $<10^{6} \mathrm{ml}^{-1}$.

Our integrated analysis also examined the independent factors which predict faster rates of suppression (Table 1). Of particular interest, concurrent progestin use as well as Caucasian ethnicity predicted faster rates of suppression: both of these are illustrated in the actual suppression rates observed (Figure 1). Caucasian men therefore exhibit faster rates of suppression initially, but the proportion that suppresses spermatogenesis ultimately is less compared with East Asian men. These data show that androgen (testosterone) only male hormonal contraceptives are unlikely to be universally applicable since suppression of sperm output to concentrations consistent with reliable contraception $\left(<10^{6} \mathrm{ml}^{-1}\right)$ in all men may not occur in a timely fashion. On the other hand, androgen-progestin male hormonal contraceptive combinations are highly promising since both the rate and extent of spermatogenic suppression are increased by up to twofold. ${ }^{27}$ However, the scantiness of androgen-progestin hormonal exposure information with contraceptive efficacy as a primary endpoint is an important limitation for the field. Whether a specific progestin is superior to another progestin is also unknown, since available studies in humans have been underpowered to determine whether certain progestins more effectively suppress sperm output than others. ${ }^{27}$ However, this is likely to be the case because progestins differ in anti-ovulatory potency, ability to support pregnancy, and binding and specific activation of progesterone relative to other steroid receptors. ${ }^{28}$ It is also not known whether the ratios of the androgen to progestin dose and levels achieved in the body are important factors for effectiveness and the development of adverse effects.

\section{UNIVERSAL REVERSIBILITY OF MALE HORMONAL CONTRACEPTIVE: ALL MEN RECOVER, BUT EAST ASIAN MEN RECOVER SLIGHTLY FASTER}

In an integrated analysis of 1549 healthy eugonadal men (965 Caucasians, 535 East Asians and 49 other ethnicities) treated with androgen or androgen-progestin male hormonal contraceptive, we showed that full recovery of spermatogenesis to concentrations consistent with normal male fertility $\left(>20 \times 10^{6} \mathrm{ml}^{-1}\right)$ is a realistic expectation for all men after treatment cessation. ${ }^{29}$ A variety of covariables, including ethnicity, independently predicts faster rates of recovery (Table 1), but not the extent of recovery. In other words, all men will eventually recover sperm output irrespective of ethnicity, although recovery is more rapid in East Asian men. Indeed, modelbased probabilities indicate that over $90 \%$ of men should have recovered sperm output to thresholds compatible with normal male fertility by 12 months, $96 \%$ (92-98) by 16 months and $100 \%$ by 24 months, irrespective of ethnicity. This is illustrated by actual recovery rates observed in 1549 men treated with various male hormonal contraceptive regimens, irrespective of type of treatment (Figure 2, using data taken from Liu et al. ${ }^{29}$ ). In particular, reversibility is not influenced by whether or not the regimen includes a progestin. Furthermore, non-recovery of sperm output has only been reported in two men after possible sterilizing processes such as epididymitis $^{18}$ and myotonic dystrophy ${ }^{30}$ interceded. Nevertheless, these data provide the strongest assurance to date of highly predictable recovery of sperm output, and semen quality, following male hormonal contraceptive. ${ }^{29}$ Although reassuring, the lack of clinical trials exceeding 18 months treatment duration and the limited number of men of African or Hispanic origin are important caveats. Longer treatment studies in more ethnically diverse populations of men are still required.

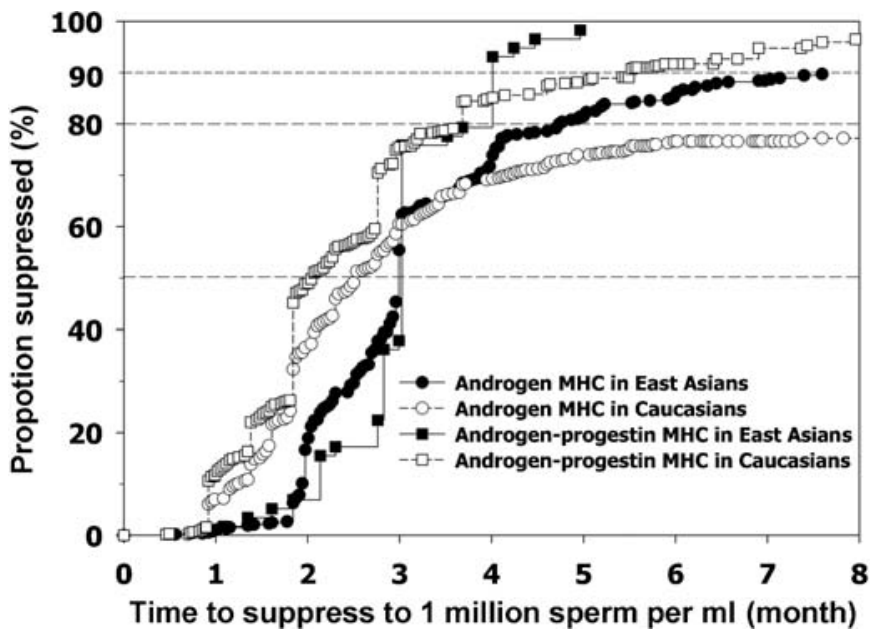

Figure 1 Suppression of sperm output during treatment with $\mathrm{MHC}$, using data taken from Ref. 27. The Kaplan-Meier graph shows the actual proportion of East Asian (dark symbol) and Caucasian (white symbol) men who have suppressed sperm concentrations to one million sperm per $\mathrm{ml}$. Men are separated depending on whether they were treated with $\mathrm{MHC}$ that comprised androgen alone (circle, $n=528$ East Asian and $n=544$ Caucasian) or androgen in combination with progestin (square, $n=58$ East Asian and $n=631$ Caucasian). MHC, male hormonal contraceptives.

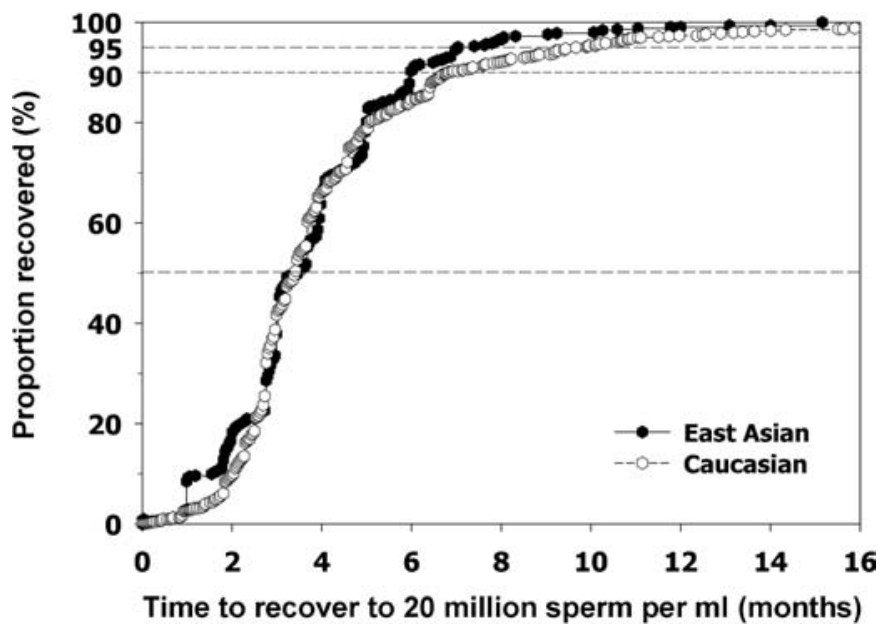

Figure 2 Recovery of sperm output after cessation of male hormonal contraceptives using data taken from Ref. 29. The Kaplan-Meier graph shows the actual proportion of East Asian (dark hexagon, $n=535$ ) and Caucasian (white hexagon, $n=965$ ) men who have recovered sperm concentrations to 20 million sperm per ml. All 1549 men treated with androgens alone or androgens with progestins are included. 
POSSIBLE MECHANISMS OF ETHNICITY RELATED DIFFERENCES IN SUPPRESSION OF SPERMATOGENESIS

Differences in testicular histomorphometry

There are some baseline differences in the male reproductive system between different ethnic groups, including differences in testicular structure and testosterone metabolism that may predispose the East Asian men to high sensitivity to steroidal contraceptives. It should be noted that the number of study participants in these studies are very small and may not be representative of the populations from which they are drawn. Comparing testicular histomorphology in Chinese versus Latino (from Central or South America) and Caucasian men who died of sudden traumatic injury, Chinese men have lower testicular parenchymal weight compared with Latino and Caucasian men. ${ }^{31}$ Testis weights were not adjusted by weight or height or body surface area which might have accounted for these reported differences in testis volume. ${ }^{32}$ Chinese and Caucasian men have less seminiferous tubular volume compared to Latino men; however, the length of seminiferous tubules per gram of parenchyma was greater in Chinese men than Latino or non-Latino Caucasian men. The volume per man of pachytene primary spermatocytes or spermatids nuclei was the lowest in Chinese men as well as the number of Sertoli cell per man; but the number of Sertoli cells per gram of parenchyma was lower in Latino men with no significant difference between Chinese or Caucasian men. The number of germ cells supported by a single Sertoli cell was lower in Chinese men. The Leydig cell cytoplasm had the greatest volume density in Chinese men but the number of Leydig cells was similar between ethnic groups. ${ }^{31}$ We reported ethnic differences in inherent susceptibility of germ cell to programmed cell death. Comparing testicular sections obtained from five Chinese men with nine non-Hispanic Caucasians, the apoptosis indices for spermatogonia, spermatocytes and spermatids were higher in Chinese men. ${ }^{33}$ These data suggest that there may be small ethnic differences in efficiency of spermatogenesis which may become more prominent when exposed to agents that increase germ call apoptosis or affect germ cell proliferation.

\section{Differences in hormone concentrations and metabolism}

Studies of serum hormone levels and production rates of testosterone showed that young Chinese men residing in China have lower testosterone production rates, total testosterone and sex hormone-binding globulin levels compared to Chinese or Caucasian men living in the United States, but their metabolic clearance rates of testosterone are comparable. $^{34,35}$ The $5 \alpha$-reduced steroids dihydrotestosterone, $3 \alpha$ $17 \beta$ androstanediol glucuronide and androsterone glucronide levels and their ratios to testosterone are lower in East Asian men, suggestive of lower $5 \alpha$-reductase enzyme activity in the East Asians. ${ }^{36-38}$ The contribution of baseline androgen levels and $5 \alpha$-reductase enzyme activity to the ethnic differences in spermatogenesis suppression in response to exogenous androgen administration deserves further investigation.

More recent studies in 5003 community-dwelling men age 65 or older from five counties (Japan, Hong Kong (China), Sweden, Tobago and United States) showed significant geographical and racial variation in steroid hormone levels and their metabolites. Unlike in younger men, total testosterone levels were higher in leaner East Asian men residing in Hong Kong (China) and Japan compared to heavier Caucasian or black men from Sweden, Tobago, United States and East Asian men resident in the United States. These differences in serum testosterone were eliminated after adjustment for body mass index. Sex hormone binding globulin was markedly higher in Japanese men compare to other countries, and as a result, the Japanese men had significantly lower free testosterone levels. Even after age and body mass index adjustments, consistent with the prior findings in younger men, the concentrations of androgen glucuronide levels were lower in East Asian men compare to Blacks and Caucasians. ${ }^{39}$ Assuming that these findings are population representative, there may be other factors including environmental and/or the health status of these older men that may influence the result. Testosterone is excreted mainly as testosterone glucuronide after metabolism that is regulated by the uridine diphospho-glucuronosyl transferases (UGT) and the UGT $2 \mathrm{~B} 17$ gene. $^{40,41}$ This gene has variable copy numbers from zero (deletion) to two (insertion) among populations. ${ }^{39,42,43}$ The deletion gene polymorphism has high frequency in East Asian, intermediate frequency in European/West Asian and low frequency in African population. ${ }^{44}$ UGT $2 \mathrm{~B} 17$ gene polymorphism contributes to ethnic differences in androgen glucuronide levels. However, the exact role of the differences in androgen glucuronidation in the suppression of spermatogenesis has not been studied directly.

\section{Differences in CAG and GGC polymorphisms of the androgen receptor}

The N-terminal of the androgen receptor contains two polymorphic polyglutamine tandem repeats that range in length from 5 to 33 glutamine residues with an average of about 20 repeats. Short CAG ( $<19$ repeats) alleles are associated with higher androgen receptor activity and have been associated with higher rate, earlier onset and aggressiveness of prostate cancer. ${ }^{45}$ More recently, reviews show that genetic epidemiology studies are difficult to interpret because of genetics diversities; for examples, CAG data showed very high within population variation whilst GGC locus may show less diversity in some populations and not others. These within- and betweenpopulation variations in the androgen receptor polyglutamine tract result in remarkable differences in CAG and GGC repeats in populations in the Mediterraneans, among sub-Sahara African, North African and south European population. ${ }^{46}$ Thus new studies with multi-ethnic and mutli-region perspective may be necessary to link androgen receptor polymorphisms to diseases. Androgen receptor CAG polymorphisms have been studied in male contraception clinical trials. Studies in Australia, ${ }^{47}$ Germany $^{48}$ and another in China ${ }^{49}$ showed that CAG polymorphism and length of the repeats were not different between those who responded to testosterone with suppression of gonadotropins and spermatogenesis and those that did not respond. However, in those that did not show complete gonadotropin suppression, the chances of achieving azoospermia was higher in those who had longer $(>22)$ CAG repeats. Thus larger multi-ethnic and multi-regional studies may be necessary to determine whether androgen receptor polymorphism contributes to ethnic differences in response to male hormonal contraceptive.

\section{Differences in gonadotropin suppressibility}

We also studied the suppressibility of gonadotropins to continuous graded infusions of testosterone in a small group of East Asian and non-Asian men. East Asian men compared to the Caucasian men had higher baseline follicle-stimulating hormone level but no significant difference in suppression in response to continuous testosterone infusion. In contrast, LH secretory pulses showed that LH pulse width, height, area and total area under the LH curve were significantly more suppressed in East Asians than in whites during the lowest infusion dose of testosterone (similar to the production rate of testosterone in man). With increasing testosterone dose, the suppression of pulsatile 
LH secretion was not different in the two ethnic groups. ${ }^{50}$ These data suggest that the heightened negative feedback mechanisms on gonadotropins by exogenous testosterone in East Asian men compared with Caucasian men can be overcome with more testosterone. These studies were done in the United States and not in East Asia, and include small number of the subjects and may not be applicable to the general populations.

\section{CONCLUSION}

Male hormonal contraceptive development has progressed significantly over the past three decades. Intramuscular injections of testosterone undecanoate alone provides adequate efficacy in Chinese men with a contraceptive failure rate of 1.0 and 1.1 per 100 men at 12 and 24 months respectively with few adverse events. ${ }^{18}$ However, ethnic differences in the suppression of spermatogenesis suggest that testosterone alone male contraceptive methods may not be suitable globally. Addition of a progestin overcomes this ethnic difference and results in adequate suppression of gonadotropins and sperm concentrations and probably contraceptive efficacy for all men. ${ }^{27} \mathrm{~A}$ multicenter study in mainly white men is currently underway in Australia, Asia, Europe and South American using 8 weekly injections of testosterone undecanoate and norethisterone enanthate and is supported by the WHO and the Contraceptive Research and Development Program. However, the best selected dose, route of administration and the type of progestin have to be determined by large clinical trials which include men from different ethnic, cultural and geographical backgrounds to ensure that the method is efficacious for all men able to overcome ethnic and environmental differences in suppression of spermatogenesis.

The future 'male pill' may become a reality with the development of orally bioavailable selective androgen receptor modulators with dual androgenic and progestational activities. Dimethandrolone undecanoate, a derivative of 19-nortestosterone possesses both in vitro and in vitro androgenic and progestational activities with prostate sparing properties, ${ }^{51,52}$ and may be one such compounds. There may be long-term issues with the use of these compounds due to lack of conversion to aromatic A-ring metabolites ${ }^{53}$ and possible effects on lipid metabolism. There are also a number of non-steroidal selective androgen receptor modulators that are in development ${ }^{54-56}$ for androgen replacement and treatment of sarcopenia. There are other non-steroidal selective androgen receptor modulators that possess both androgen and progestational activities that may be effective in suppressing gonadotropins, maintaining androgenic actions, but sparing the stimulatory effect on the prostate gland while the effects on lipids and long-term cardiovascular health are not known. These agents could be ideal compounds for male contraception. All new entities will have to be tested in multi-ethnic studies to determine safety and effectiveness on spermatogenesis suppression as a candidate for hormonal male contraceptive development. With improved safety and effectiveness and the availability of orally active compounds, the new era of male contraceptive may then be accepted by men and their partners.

\section{AUTHOR CONTRIBUTIONS}

NI reviewed the topic, wrote sections of the manuscript. PYL performed the data analyses described in the manuscript and wrote sections. RSS and CW revised and edited.

\section{COMPETING FINANCIAL INTERESTS}

NI and PYL have nothing to disclose. CW has received research support from GlaxoSmithKline, Repros Therapeutics, research materials from Besins Health Care, and is a consultant to GlaxoSmithKline and Lilly. RS is a consultant for Abbott (Solvay), Clarus Therapeutics, Endo Pharmaceuticals, GlaxoSmithKline, Lilly, Repros Therapeutics, and has received research support from Lilly and Clarus Therapeutics.

\section{ACKNOWLEDGMENTS}

This review was supported by Endocrinology and Metabolism Training Grant (T32 DK007571), the General Clinical Research Center at Harbor UCLA (RR MO1 00425), and the NICHD through the Contraceptive Clinical Network Centers (Male Area) (HHSN275200403369I) to Los Angeles Biomedical Research Institute.

1 Amory JK, Bremner W. Endocrine regulation of testicular function in men: implications for contraceptive development. Mol Cell Endocrinol 2002; 186: 205-9.

2 Wang C, Swerdloff RS. Male hormonal contraception. Am J Obstet Gynecol 2004 190: S60-8.

3 Nieschlag E, Henke A. Hopes for male contraception. Lancet 2005; 365: 554-6.

4 Anderson RA, Baird DT. Male contraception. Endocr Rev 2002; 23: 735-62.

5 Kamischke A, Nieschlag E. Progress towards hormonal male contraception. Trends Pharmacol Sci 2004; 25: 49-57.

6 Page ST, Amory JK, Bremner WJ. Advances in male contraception. Endocr Rev 2008 29: 465-93.

7 Nieschlag E. Clinical trials in male hormonal contraception. Contraception 2010; 82 : 457-70.

8 O'Donnell L, McLachlan RI, Wreford NG, de Kretser DM, Robertson DM. Testosterone withdrawal promotes stage-specific detachment of round spermatids from the rat seminiferous epithelium. Biol Reprod 1996; 55: 895-901.

9 O'Donnell L, Narula A, Balourdos G, Gu YQ, Wreford NG et al. Impairment of spermatogonial development and spermiation after testosterone-induced gonadotropin suppression in adult monkeys (Macaca fascicularis). J Clin Endocrinol Metab 2001; 86: 1814-22.

10 McLachlan RI, O’Donnell L, Meachem SJ, Stanton PG, de Kretser DM et al Identification of specific sites of hormonal regulation in spermatogenesis in rats, monkeys, and man. Recent Prog Horm Res 2002; 57: 149-79.

11 McLachlan RI, O'Donnell L, Meachem SJ, Stanton PG, de Kretser DM et al. Hormona regulation of spermatogenesis in primates and man: insights for development of the male hormonal contraceptive. J Androl 2002; 23: 149-62.

12 Sinha Hikim AP, Rajavashisth TB, Sinha HI, Lue Y, Bonavera JJ et al. Significance of apoptosis in the temporal and stage-specific loss of germ cells in the adult rat after gonadotropin deprivation. Biol Reprod 1997; 57: 1193-201.

13 Hikim AP, Wang C, Leung A, Swerdloff RS. Involvement of apoptosis in the induction of germ cell degeneration in adult rats after gonadotropin-releasing hormone antagonist treatment. Endocrinology 1995; 136: 2770-5.

14 Vera Y, Erkkila K, Wang C, Nunez C, Kyttanen S et al. Involvement of p38 mitogenactivated protein kinase and inducible nitric oxide synthase in apoptotic signaling of murine and human male germ cells after hormone deprivation. Mol Endocrinol 2006 20: 1597-609.

15 World Health Organization Task Force on Methods for the Regulation of Male Fertility. Contraceptive efficacy of testosterone-induced azoospermia in normal men. World Health Organization Task Force on methods for the regulation of male fertility. Lancet 1990; 336: 955-9.

16 World Health Organization Task Force on Methods for the Regulation of Male Fertility. Contraceptive efficacy of testosterone-induced azoospermia and oligozoospermia in normal men. Fertil Steril 1996; 65: 821-9.

17 Turner L, Conway AJ, Jimenez M, Liu PY, Forbes E et al. Contraceptive efficacy of a depot progestin and androgen combination in men. J Clin Endocrinol Metab2003; 88: 4659-67.

18 Gu Y, Liang X, Wu W, Liu M, Song S et al. Multicenter contraceptive efficacy trial of injectable testosterone undecanoate in Chinese men. J Clin Endocrinol Metab 2009; 94: 1910-5.

19 Gu YQ, Wang XH, Xu D, Peng L, Cheng LF et al. A multicenter contraceptive efficacy study of injectable testosterone undecanoate in healthy Chinese men. J Clin Endocrinol Metab 2003; 88: 562-8.

20 Handelsman DJ. Editorial: hormonal male contraception-lessons from the East when the Western market fails. J Clin Endocrinol Metab 2003; 88: 559-61.

21 Nieschlag E. Male hormonal contraception: love's labour's lost? J Clin Endocrinol Metab 2009; 94: 1890-2.

22 Glasier AF, Anakwe R, Everington D, Martin CW, van der Spuy Z et al. Would women trust their partners to use a male pill? Hum Reprod 2000; 15: 646-9.

23 Martin CW, Anderson RA, Cheng L, Ho PC, van der Spuy Z et al. Potential impact of hormonal male contraception: cross-cultural implications for development of novel preparations. Hum Reprod 2000; 15: 637-45.

24 Heinemann K, Saad F, Wiesemes M, White S, Heinemann L. Attitudes toward male fertility control: results of a multinational survey on four continents. Hum Reprod 2005; 20: 549-56.

25 Handelsman DJ, Farley TM, Peregoudov A, Waites GM. Factors in nonuniform induction of azoospermia by testosterone enanthate in normal men. World Health 
Organization Task Force on Methods for the Regulation of Male Fertility. Fertil Steril 1995; 63: 125-33.

26 Wu FC, Farley TM, Peregoudov A, Waites GM. Effects of testosterone enanthate in normal men: experience from a multicenter contraceptive efficacy study. World Health Organization Task Force on Methods for the Regulation of Male Fertility. Fertil Steril 1996; 65: 626-36.

27 Liu PY, Swerdloff RS, Anawalt BD, Anderson RA, Bremner WJ et al. Determinants of the rate and extent of spermatogenic suppression during hormonal male contraception: an integrated analysis. J Clin Endocrinol Metab 2008; 93: 1774-83.

28 Sitruk-Ware R. New progestagens for contraceptive use. Hum Reprod Update 2006; 12: $169-78$.

29 Liu PY, Swerdloff RS, Christenson PD, Handelsman DJ, Wang C et al. Rate, extent and modifiers of spermatogenic recovery after hormonal male contraception: an integrated analysis. Lancet 2006; 367: 1412-20.

30 Turner L, Conway AJ, Jimenez M, Liu PY, Forbes E et al. Contraceptive efficacy of a depot progestin and androgen combination in men. J Clin Endocrinol Metab2003; 88: 4659-67.

31 Johnson L, Barnard JJ, Rodriguez L, Smith EC, Swerdloff RS et al. Ethnic differences in testicular structure and spermatogenic potential may predispose testes of Asian men to a heightened sensitivity to steroidal contraceptives. J Androl 1998; 19: 348-57.

32 Handelsman DJ, Staraj S. Testicular size: the effects of aging, malnutrition, and illness. J Androl 1985; 6: 144-51.

33 Hikim AP, Wang C, Lue Y, Johnson L, Wang XH et al. Spontaneous germ cell apoptosis in humans: evidence for ethnic differences in the susceptibility of germ cells to programmed cell death. J Clin Endocrinol Metab 1998; 83: 152-6.

34 Santner SJ, Albertson B, Zhang GY, Zhang GH, Santulli M et al. Comparative rates of androgen production and metabolism in Caucasian and Chinese subjects. J Clin Endocrinol Metab 1998; 83: 2104-9.

35 Wang C, Catlin DH, Starcevic B, Leung A, DiStefano E et al. Testosterone metabolic clearance and production rates determined by stable isotope dilution/tandem mass spectrometry in normal men: influence of ethnicity and age. J Clin Endocrinol Metab 2004; 89: 2936-41.

36 Lookingbill DP, Demers LM, Wang C, Leung A, Rittmaster RS et al. Clinical and biochemical parameters of androgen action in normal healthy Caucasian versus Chinese subjects. J Clin Endocrinol Metab 1991; 72: 1242-8.

37 Wu AH, Whittemore AS, Kolonel LN, John EM, Gallagher RP et al. Serum androgens and sex hormone-binding globulins in relation to lifestyle factors in older AfricanAmerican, white, and Asian men in the United States and Canada. Cancer Epidemiol Biomarkers Prev 1995; 4: 735-41.

38 Ross RK, Bernstein L, Lobo RA, Shimizu H, Stanczyk FZ et al. 5-alpha-reductase activity and risk of prostate cancer among Japanese and US white and black males. Lancet 1992; 339: 887-9.

39 Orwoll ES, Nielson CM, Labrie F, Barrett-Connor E, Cauley JA et al. Evidence for geographical and racial variation in serum sex steroid levels in older men. J Clin Endocrinol Metab 2010; 95: E151-60.

40 Schulze JJ, Lundmark J, Garle M, Skilving I, Ekstrom L et al. Doping test results dependent on genotype of uridine diphospho-glucuronosyl transferase 2B17, the major enzyme for testosterone glucuronidation. J Clin Endocrinol Metab 2008; 93 : 2500-6.

41 Swanson C, Mellstrom D, Lorentzon M, Vandenput L, Jakobsson J et al. The uridine diphosphate glucuronosyltransferase 2B15 D85Y and 2B17 deletion polymorphisms predict the glucuronidation pattern of androgens and fat mass in men. J Clin Endocrinol Metab 2007; 92: 4878-82.

42 Jakobsson J, Ekstrom L, Inotsume N, Garle M, Lorentzon M et al. Large differences in testosterone excretion in Korean and Swedish men are strongly associated with a UDPglucuronosyl transferase 2B17 polymorphism. J Clin Endocrinol Metab 2006; 91: 687-93.

43 Vandenput L, Labrie F, Mellstrom D, Swanson C, Knutsson T et al. Serum levels of specific glucuronidated androgen metabolites predict BMD and prostate volume in elderly men. J Bone Miner Res 2007; 22: 220-7.

44 Xue Y, Sun D, Daly A, Yang F, Zhou X et al. Adaptive evolution of UGT2B17 copynumber variation. Am J Hum Genet 2008; 83: 337-46.

45 Giovannucci E, Stampfer MJ, Krithivas K, Brown M, Dahl D et al. The CAG repeat within the androgen receptor gene and its relationship to prostate cancer [published erratum appears in Proc Natl Acad Sci USA 1997 Jul 22;94(15):8272]. Proc Natl Acad Sci USA 1997; 94: 3320-3.

46 Esteban E, Rodon N, Via M, Gonzalez-Perez E, Santamaria J et al. Androgen receptor CAG and GGC polymorphisms in Mediterraneans: repeat dynamics and population relationships. J Hum Genet 2006; 51: 129-36.

47 Yu B, Handelsman DJ. Pharmacogenetic polymorphisms of the AR and metabolism and susceptibility to hormone-induced azoospermia. J Clin Endocrinol Metab 2001; 86: 4406-11.

48 Eckardstein SV, Schmidt A, Kamischke A, Simoni M, Gromoll J et al. CAG repeat length in the androgen receptor gene and gonadotrophin suppression influence the effectiveness of hormonal male contraception. Clin Endocrinol (Oxf) 2002; 57: 647-55.

49 Li JW, Gu YQ. Predictors for partial suppression of spermatogenesis of hormonal male contraception. Asian J Androl 2008; 10: 723-30.

50 Wang C, Berman NG, Veldhuis JD, Der T, McDonald V et al. Graded testosterone infusions distinguish gonadotropin negative-feedback responsiveness in Asian and white men—a Clinical Research Center study. J Clin Endocrinol Metab 1998; 83: 870-6.

51 Attardi BJ, Hild SA, Reel JR. Dimethandrolone undecanoate: a new potent orally active androgen with progestational activity. Endocrinology 2006; 147: 3016-26.

52 Cook CE, Kepler JA. 7alpha,11beta-Dimethyl-19-nortestosterone: a potent and selective androgen response modulator with prostate-sparing properties. Bioorg Med Chem Lett 2005; 15: 1213-6.

53 Attardi BJ, Pham TC, Radler LC, Burgenson J, Hild SA et al. Dimethandrolone (7alpha, 11 beta-dimethyl-19-nortestosterone) and 11 beta-methyl-19-nortestosterone are not converted to aromatic A-ring products in the presence of recombinant human aromatase. J Steroid Biochem Mol Biol 2008; 110: 214-22.

54 Mohler ML, Bohl CE, Jones A, Coss CC, Narayanan R et al. Nonsteroidal selective androgen receptor modulators (SARMs): dissociating the anabolic and androgenic activities of the androgen receptor for therapeutic benefit. J Med Chem 2009; 52: 3597-617.

55 Narayanan R, Mohler ML, Bohl CE, Miller DD, Dalton JT. Selective androgen receptor modulators in preclinical and clinical development. Nucl Recept Signal 2008; 6: e010.

56 Jones A, Hwang DJ, Narayanan R, Miller DD, Dalton JT. Effects of a novel selective androgen receptor modulator on dexamethasone-induced and hypogonadism-induced muscle atrophy. Endocrinology 2010; 151: 3706-19. 